\title{
External Fixator as a Saviour in the Management of Aneurysmal Bone Cyst with Physeal Extension in Pathological Fracture of the Proximal Femur: A Case Report with a Review of Literature
}

\author{
Sudhir S Kushwaha ${ }^{1}$, Atil Kumar Lal ${ }^{1}$, Nitish Kumar ${ }^{1}$, Ajay Bharti ${ }^{1}$ \\ Learning Point of the Article: \\ External fixator can be a saviour in management of pathological fracture of proximal femur secondary to benign bone tumors.
}

\section{Abstract}

Introduction: Aneurysmal bone cysts (ABC's) are expansile, tumour-like vascular lesion. They are more commonly seen in the metaphyseal region of long bones. They are benign lesion although malignant transformation has been reported. Usually presents in the first three decades of life. Common presentation is pain, swelling, or fracture. Proximal femur with ABC's is a rare entity and with physeal extension is even sparse.

Case Report: A 13- year-. old female presented in the orthopaedic emergency with complaints of pain in the right hip region following a trivial fall. Following trauma, the patient was unable to stand or walk. On examination, there was tenderness in Scarpa's triangle, straight leg raise test was not possible and limb was in external rotation. Plain radiography revealed an inter-trochanteric fracture with cystic lesion in the proximal femur extending till until epiphysis. MRI of the proximal femur showed an air fluid level with septations and soft- tissue oedema suggestive of aneurysmal bone cyst $\mathrm{ABC}$ 's.

The patient was managed by intra-lesional curettage with fibular strut grafting along with cancellous bone graft and fixation by Uni-planar external fixator.

Conclusion: Pathological Fractures fractures of proximal femur management is are a challenge for an orthopaedic surgeon due to its location and biomechanical factors. Treatment of proximal femur ABC's should be case dependent. In our opinion, aneursymal bone cyst of the proximal femur with physeal extension can be managed by external fixation along with extensive curettage and bone graft.

Keywords: Aneurysmal bone cyst, proximal femur, external fixation

\section{Introduction}

Aneurysmal bone cysts (ABC's) are benign, tumor-like, vascular lesions comprised blood-filled channels separated by fibrous Septa [1]. They have an expansile characteristic, which leads to pain, deformity, disruption of joint spaces, and growth plates.

ABC's normally involves metaphyseal region of long bones (67\%); however, they are also seen in vertebrae (15\%), pelvis, and craniofacial bones [2]. They are mainly seen in first three decades of life (95\%) [3]. Although benign malignant transformation has been seen in a few cases. Pathological fracture occurs in about $8 \%$ of $\mathrm{ABCs}$ [4].

Evaluation of $A B C$ 's is mainly by imaging studies, which give us a major clue of diagnosis. A typical expansile lesion with fine septations and characteristic eggshell appearance is seen on plain radiograph, MRI shows a more descriptive characteristic by showing air fluid levels as focal areas of hyper-intense signal on both T1 and T2 [5]. However, histological confirmation is still necessary.

Various treatment modalities of ABC's have been demonstrated by various surgeons; however, intra-lesional curettage is most commonly done. Other surgical methods include curettage

\begin{tabular}{|c|c|c|c|c|}
\hline \multirow[b]{2}{*}{ Access this article online } & \multicolumn{3}{|c|}{ Author's Photo Gallery } & \\
\hline & & & & \\
\hline $\begin{array}{c}\text { Website: } \\
\text { www.jocr.co.in }\end{array}$ & Dr. Sudhir S Kushwaha & Dr. Atil Kumar Lal & Dr. Nitish Kumar & Dr. Ajay Bharti \\
\hline $\begin{array}{c}\text { DOI: } \\
10.13107 / \text { jocr.2021.v11.i04.2128 }\end{array}$ & \multicolumn{4}{|c|}{$\begin{array}{l}\text { 'Department of Orhtopaedics(Orthopedics), AIIMS, Gorakhpur, Uttar Pradesh. India. } \\
\text { Address of Correspondence: } \\
\text { Dr. Atil Kumar Lal, } \\
\text { Department of Orthopaedics AIIMS, Gorakhpur, Uttar Pradesh, India. } \\
\text { E-mail: atil27@gmail.com }\end{array}$} \\
\hline
\end{tabular}

Journal of Orthopaedic Case Reports | pISSN 2250-0685 | eISSN 2321-3817 | Available on www.jocr.co.in | doi:10.13107/jocr.2021.v11.i04.2128 This is an Open Access article distributed under the terms of the Creative Commons Attribution Non-Commercial License (http://creativecommons.org/licenses/by-nc/3.0) which permits unrestricted non-commercial use, distribution, and reproduction in any medium, provided the original work is properly cited. 


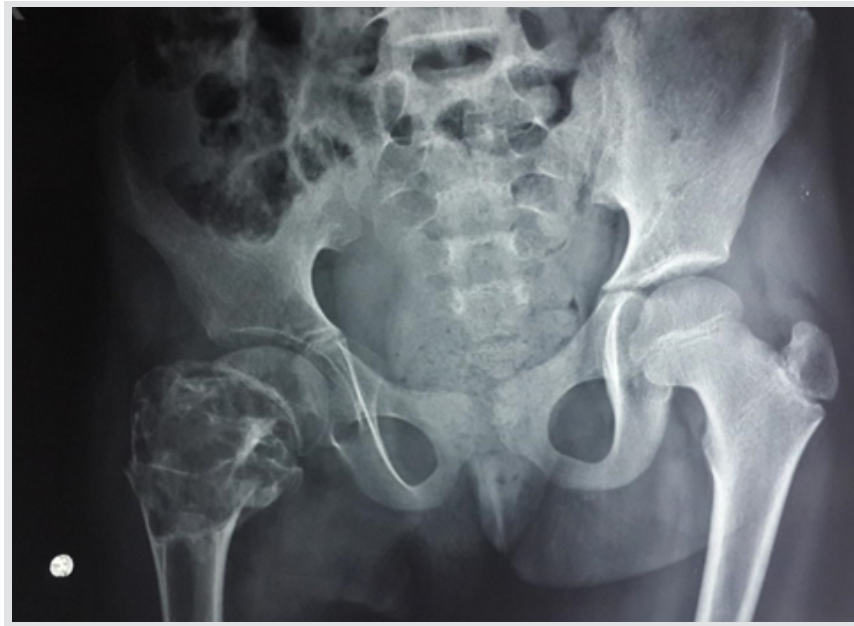

Figure 1: Pre-operative radiograph showing an expansile cystic lesion with fracture of proximal femur.

with cementation and bone graft, en bloc excision, fibrosing agents or bone marrowinjections, curettage with locally applied adjutants, for example, as liquid nitrogen and argon beam photo-coagulation [6].

However, treatment decision mainly depends on the size of the lesion and region of the bone involved.

We present here a case of 11-year-old female with $A B C$ of proximal femur, which because of its location was a challenge for the team of surgeons.

\section{Case Report}

A 13-year-old female presented in the orthopedic emergency with complaints of pain in the right hip region following a trivial fall. Following trauma, the patient was unable to stand or walk. On examination, there was tenderness in Scarpa's triangle, straight leg raise test was not possible and limb was in external rotation.

Plain radiography revealed an inter-trochanteric fracture with cystic lesion in the proximal femur extending until epiphysis (Fig. 1). MRI of the proximal femur showed an air fluid level with septations and soft-tissue edema suggestive of $A B C$. Routine hematological parameters were within the normal range except a slight elevation of serum alkaline phosphatase.

Surgical decision making was challenging due to the location and size of the lesion. After written consent and explaining the prognosis, the patient was planned for surgical intervention. The patient was managed by intra-lesional curettage with fibular strut grafting along with cancellous bone graft and fixation by Uni-planar external fixator with 2 Schanz screw in supra-acetabular region, 2 in neck femur, and 2 in femoral shaft (Fig. 2). The curettage material was then sent for histopathological evaluation. Hematoxylin and Eosin (H\&E) sections show blood filled spaces separated by cellular septa containing fibroblasts, giant cells, and woven bone (Fig. 4).

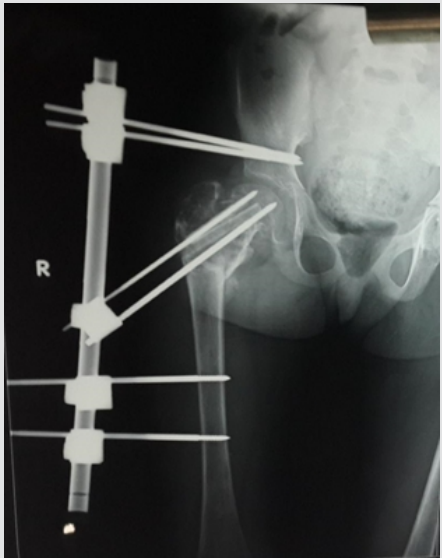

Figure 2: Post-operative radiograph showing curettage of lesion with fibular strut graft along with cancellous bone graft and stabilized by external fixator.

Post-surgery the patient was not allowed to bear weight for initial 6 weeks, followed by partial weight-bearing with the help of walker for another 6 weeks. Fixator removal was done at 12 weeks; only once radiological signs of union were seen. A shortening of $2.5 \mathrm{~cm}$ was seen in the involved limb, which was managed by shoe raise. There was no obvious pin tract infection.

At 5 months follow-up (Fig. 3), the patient was pain-free and was able to walk without support. There was no evidence of recurrence at 1-year follow up.

\section{Discussion}

Surgical decision is the main key factor in managing tumor lesion. $\mathrm{ABC}$ is due to its expansile nature has various presentation. Although it more commonly involves metaphyseal region of the bone, physeal extension has also been noticed [7]. Levent et al. also reported a similar case where ABC

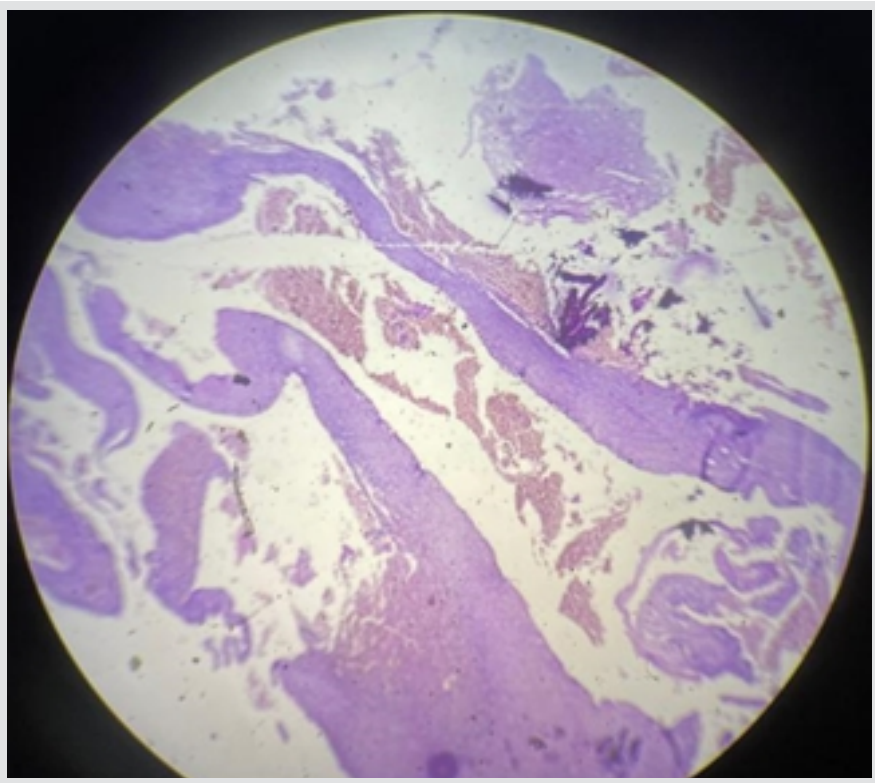

Figure 4: H\&E sections showing blood filled spaces separated by cellular septa containin fibroblasts, giant cells, and woven bone. 
was present in a neck of femur of a 21-year-old male, they managed him by distractor along with curettage and penalization(Phenolization) [8].

Various treatment modalities have been suggested in the literature. However, management solely is depended on the size and location of the lesion. Large lesion is usually managed by intra-lesional curettage with bone substitute and graft along with bone cement if required. Sclerosing agents have been found to be less effective in the management of larger lesions due to need of multiple injection and prolong follow-up, Otte et al. in his study on 38 patients of ABC's found that delay in healing is one of the major cause of lost follow-up of the patients. Proximal femur involvement of $\mathrm{ABC}$ is a rare entity and its extension until physis is sparser. Proximal femur being one of the major weight-bearing regions on involvement becomes venerable to pathological fracture. Due to its location, complete resection of tumor along with fixation and filling of the defect becomes a challenging job for the surgeon. Khalifa et al. in his study on eight patients showed that extended curettage with bone graft and internal fixation has been the treatment of choice for such fracture by many surgeons [9].

Due to its aggressive nature, $\mathrm{ABC}$ has also seen a high rate of recurrence. The rate of recurrence of $\mathrm{ABC}$ is as high as $12-30 \%$ $[10,11]$.

Lin et al. in his study has hypothesized that plays an important role; lesion near the Physis is more prone to recur mainly because of technical and biological challenges [12]. Out of all the metaphyseal lesion proximal femur involvement is not uncommon, Makin et al. in his study on 150 juxta physeal ABC's found out that proximal femur involvement was around $46 \%$ [13].

In our case, the choice of fixation was our main concern due to the extension of the lesion until physis. Hence, internal fixation devices would not have given us more stability. Levent et al. in his study on 18 patients also described the use of external fixators in musculoskeletal tumors [14]. Therefore, we went with Uni-planar external fixation, which gave stable fixation and helped in weight-bearing. Moreover, we choose fibular strut graft, which provided structural stability as well as filled the large defect.

\section{Conclusion}

Pathological fractures of proximal femur management are a challenge for an orthopedic surgeon due to its location and biomechanical factors. Treatment of proximal femur ABC's should be case dependent. In our opinion, aneursymal bone cyst of the proximal femur with physeal extension can be managed by external fixation along with extensive curettage and bone graft.

\section{Clinical Message}

External fixators can be used as a treatment modality for pathological fracture of the proximal femur with physeal extension.

\section{References}

1. Stevens KJ, Stevens JA. Aneurysmal bone cysts. In: StatPearls. Treasure Island, FL: StatPearls Publishing; 2020.

2. Mascard E, Gomez-Brouchet A, Lambot K. Bone cysts: Unicameral and aneurysmal bone cyst. Orthop Traumatol Surg Res 2015;101:S119-27.

3. Bonakdarpour A, Levy WM, Aegerter E. Primary and secondary aneurysmal bone cyst: A radiological study of 75 cases. Radiology 1978;126:75-83.

4. Pawar E, Harsoor A, Ramteke U, Yadav AK, Aher G. Management of aneurysmal bone cyst of proximal femur with a pathologic intertrochanteric femur fracture with an intramedullary nail and bone graft: A case report. Int J Orthop Sci 2019;5:156-9.

5. Tsai JC, Dalinka MK, Fallon MD, Zlatkin MB, Kressel HY. Fluid-fluid level: A nonspecific finding in tumors of bone and soft tissue. Radiology 1990;175:779-82.
6. Cottalorda J, Kohler R, Chotel F, de Gauzy JS, Lefort G, Louahem D, et al. Recurrence of aneurysmal bone cysts in young children: A multicentre study. J Pediatr Orthop B 2005; 14:212-8.

7. McCarthy SM, Ogden JA. Epiphyseal extension of an aneurysmal bone cyst.J Pediatr Orthop 1982;2:171-5.

8. Eralp L, Eren I. Femoral neck aneurysmal bone cyst treated with articulated distraction and grafting. In: Limb Lengthening and Reconstruction Surgery Case Atlas. Switzerland: Springer International Publishing; 2015.p. 1.

9. Khalifa YE, El-Kady HA, Abdel-Aal AM, Khalil AM. Pathologic proximal femoral fracture complicating aneurysmal bone cyst: Management and alternatives of fixation in eight patients. Curr Orthop Pract 2010;21:3905.

10. Campanacci M, Capanna R, Picci P. Unicameral and 
aneurysmal bone cysts. Clin Orthop Relat Res 1986;204:25-36.

11. Capanna R, Bettelli G, Biagini R, Ruggieri P, Bertoni F, Campanacci M. Aneurysmal cysts of long bones. Ital J Orthop Traumatol 1985;11:409-17.

12. Lin PP, Brown C, Raymond AK, Deavers MT, Yasko AW. Aneurysmal bone cysts recur at juxtaphyseal locations in skeletally immature patients. Clin Orthop Relat Res 2008;466:722-8.
13. Mankin HJ, Hornicek FJ, Ortiz-Cruz E, Villafuerte J, Gebhardt MC. Aneurysmal bone cyst: A review of 150 patients.J Clin Oncol 2005;23:6756-62.

14. Eralp L, Toker B, Akgül T, Ozger H, Kocaoğlu M, Hayat S. Applications of external fixation for management of complications associated with musculoskeletal tumors and related surgery. Acta Orthop Traumatol Turc 2004;43:21922.

\section{Conflict of Interest: Nil}

Source of Support: Nil

Consent: The authors confirm that informed consent was obtained from the patient for publication of this case report

\section{How to Cite this Article}

Kushwaha SS, Lal AK, Kumar N, Bharti A. External Fixator as a Savior in the Management of Aneurysmal Bone Cyst with Physeal Extension in Pathological Fracture of the Proximal Femur: A Case Report with a Review of Literature. Journal of Orthopaedic Case Reports 2021 April;11(4): 6-9 